\title{
Monitoring of Sobradinho landslide (Brasília, Brazil) and a prototype vertical slope by time-lapse interferometry
}

\author{
Yawar Hussain ${ }^{1,2 *}$ (D), Martin Cardenas-Soto ${ }^{3}$ (D), Rogerio Uagoda ${ }^{4}$ (D), Salvatore Martino ${ }^{5}$ (D), \\ Juan Rodriguez-Rebolledo' (D), Omar Hamza ${ }^{6}$ (D), Hernan Martinez-Carvajal ${ }^{7}$ (D)
}

\begin{abstract}
The application of geophysical monitoring technologies may offer an opportunity to understand the dynamic of slopes in response to factors triggering their instability. In this study, Ambient Noise Interferometry was used as a monitoring approach on a man-made reduced-scale vertical slope and on a natural-scale landslide in Sobradinho (Brazil), under the influence of mechanical stress and rainfall, respectively. For both experiments, we adopted similar data acquisition system and processing workflow. After preprocessing of ambient seismic noise, the time-lapse changes were determined in terms of relative velocity changes using the moving window cross spectral technique. For the vertical slope, terrestrial laser scanning was also performed to detect crack or fissure generation. The prototype experiment results showed a decreasing trend of relative velocity changes and reached a minimum value of $-0.6 \%$ at the end of the experiment. No change was detected on the digital elevation model that was computed from terrestrial laser scanning images, due to the absence of centimeter scale superficial fissures. At natural scale (Sobradinho landslide), no significant variation in relative velocity changes was detected for the rainy and non-rainy days, mainly because of the inadequate change in the degree of saturation, which was found within a relatively short period of data acquisition.
\end{abstract}

KEYWORDS: Ambient seismic noise; rainfall; clayey landslide; terrestrial laser scanning.

\section{INTRODUCTION}

Landslides may severely impact human lives and the environmental resources of the affected region. Shallow and rainfall-triggered sliding of clayey soils has a greater share in global terrestrial hazards. In Brazil, the events of 1967 and, more recently of, 2011 in Rio de Janeiro are a tragic reminder of the damage caused by soil mass movements (Hussain et al. 2017). Such shallow and clay-rich landslides are usually triggered by intense rainfalls (Ehrlich et al. 2018) that lead to pore

\footnotetext{
${ }^{1}$ Department of Civil and Environmental Engineering, Universidade de Brasília - Brasília (DF), Brazil. E-mail: yawar.pgn@gmail.com

${ }^{2}$ Institute of Geosciences, Universidade de Brasília - Brasília (DF), Brazil. E-mail: yawar.pgn@gmail.com

${ }^{3}$ Engineering Faculty, National Autonomous University of Mexico Coyoacán, Mexico City, Mexico. E-mail: martinc@unam.mx

${ }^{4}$ Post-Graduation Program in Geography, Universidade de Brasília Brasília (DF), Brazil. E-mail: rogeriouagoda@unb.br

${ }^{5}$ Department of Earth Sciences and Research Center for Geological Risks (CERI), University of Rome "Sapienza" - Roma, Italy.

E-mail: salvatore.martino@uniroma1.it

${ }^{6}$ College of Engineering and Technology, University of Derby - Derby, United Kingdom. E-mail: o.hamza@derby.ac.uk

${ }^{7}$ Faculty of Mines, National University of Colombia - Medellin, Colombia. E-mail: hmartinezc30@gmail.com

${ }^{*}$ Corresponding author.
}

(c) 2019 The autors. This is an open access article distributed under the terms of the Creative Commons license. water pressure build up, reduction in effective stress, and variations in elastic moduli and density of the subsurface material (Planès et al. 2015). Along with pore-pressure, the changes in rheology of landslide mass and in the properties of the involved materials can also trigger their reactivation. This has been verified in a laboratory-scaled experiment supported by monitoring the transition from solid to liquid behavior (Mainsant et al. 2012a). The same triggering mechanisms are associated with many other near-surface ground engineering processes, and their monitoring is an important step in mitigation of hazards (Planès et al. 2015).

For monitoring such hazardous processes and their progress towards failure, a continuous source of energy is required, which can be provided by ambient noise and vibrations due to human activities, i.e. not from earthquakes, by the action of wind or ocean waves. Based on frequency content, the ambient noise is composed of two typologies of sources: microtremors $(>1 \mathrm{~Hz})$ and microseism $(<1 \mathrm{~Hz})$ (Hussain et al. 2017). Landslide monitoring through ambient noise has many benefits (Hussain et al. 2019), which can be summarized as follows:

- it excludes source parameters, such as focal mechanism and source;

- it provides dense and continuous data availability that leads to high temporal coverage;

- it is non-destructive (D’Hour 2015).

For monitoring purposes, ambient noise interferometry (ANI) makes use of the noise wavefield at two stations (Sens-Schönfelder \& Wegler 2006, Voisin et al. 2016, 
Bièvre et al. 2018, Czarny et al. 2018, 2019). The interferometry concept was applied to geophysics by Claerbout (1986), following earlier successful applications in Astronomy. In this technique, Green's function and impulse-response are extracted from the ambient noise recorded at two stations, which accounts for the wave propagation between two sensors and provide information on the stress material state (Bièvre et al. 2018).

The ANI was applied in the past for monitoring stress changes with magma migration in active volcanoes (Obermann et al.2013), active fault (Wegler \& Sens-Schöonfelder 2007), gold and silver mining (Grêt et al. 2006), and in deep earth (Boué et al. 2013, Lin et al. 2013). It has also been used for monitoring civil and geotechnical structures, such as buildings (Snieder \& Safak 2006, Nakata et al. 2013, Nakata \& Snieder 2013) and landslide (Renalier et al. 2010, Mainsant et al. 2012b, Harba \& Pilecki 2017, Milesi 2016, Bièvre et al. 2018), as well as temporal changes in earthen embankments at a laboratory scale experiment (Planès et al.2015) and tailings dams (Olivier et al. 2017).

However, further applications of ANI are required to improve our understanding of the dynamic of slopes in response to different factors that trigger their instability. The present study applied ANI on two different field experiments (i.e. two different experimental sites), for examining the effect of rainfall and mechanical loading on slopes. The first experiment was conducted on an excavation under controlled conditions to represent a reduced-scale vertical slope (a man-made excavation cut), while the second one was carried out under natural conditions at a selected landslide in Sobradinho (Brazil), representing many similar landslides in the region. In the first site test, the vertical load (as a possible landslide trigger) was applied on the top of the vertical slope (excavation). The slope was monitored by measuring the ambient vibrations propagating in clayey deposits. The slope surface was monitored throughout the experiment with ANI and terrestrial laser scanner (TLS) in order to identify the emergence of fissures or cracks. In the second sites, the ANI was applied for monitoring the temporal changes in the rheology, related parameter values or any mechanism created in response to changes in the degree of saturation of Sobradinho landslide mass during rainy days. Based on experimental data, the relation between the applied load and the degree of saturation with relative velocity changes $(\mathrm{dV} / \mathrm{V})$ were analyzed and discussed.

\section{MATERIAL AND METHODS}

\section{Reduced-scale experiment (vertical slope)}

A two-meter wide and 1.5-meter deep excavation was dug in the experimental field of the Department of Civil and Environmental Engineering, University of Brasília, Brasília, Brazil. This excavation is a prototype experiment that is analogous to a vertical slope in tropical clays, widely outcropping in the Brasília region. The seismic acquisition system consisted of three seismometers, Ref-Tek-130 data-loggers and GPS locks. Data were recorded at a sampling rate of 1,000 samples per second (SPS). The sensors were time synchronized through GPS locks. Recording took place on Wednesday night (February $21^{\text {st }}$ of 2018) between $10 \mathrm{pm}$ and 2 am (local time) when no transients were present due to local human noise and traffic.

The experiment goal was to understand the seismic response of tropical clays (one of the most typical Brazilian soils) under different loading conditions. This was achieved by applying vertical load on a $1 \times 1 \mathrm{~m}$ steel plate placed on the top of the vertical slope. The conventional choice of direct loading was excluded because it would make the loading mechanism unstable and risky. This problem was solved by the construction of reaction piles/shallow foundations. The design of the reaction piles was based on the calculation of soil parameters (e.g., Mota, 2003).

The following loading mechanism was set in place to conduct the test (Fig. 1):

- there were two reinforced concrete piles (reaction piles), $0.8 \mathrm{~m}$ diameter and $12 \mathrm{~m}$ deep piles;

- vertical stress was applied on the top surface of each pile;

- on the top of the piles, two double T-shaped rigid steel beams were placed supported by concrete blocks stands restricting their movement;

- below the steel beam and in between the two consecutive piles, a soil area of $1 \mathrm{~m}^{2}$ was leveled;

- this formed the base for the installation of a hydraulic jack, which was in turn connected to a manually operated oil pump. By increasing the oil pressure, the hydraulic jack was pushed against the steel beam and the soil surface, thus increasing the load on the vertical slope crown;

- four extensometers were attached to the hydraulic jack and the steel beam for monitoring the vertical displacement of the slope crown from four sides. All parts of the loading mechanism were leveled to ensure that the load was applied in the vertical position. This way (of loading mechanism) provided a healthy and hazard-free working environment (Yfantis et al. 2013).

The processing of the TLS data was divided into two phases: laser data preliminary treatment and point cloud analysis. The preliminary treatment constitutes noise reduction (filtering), point cloud generation and geo-referencing. This leads to noise-free point cloud that was used in the next stage of processing, in which triangulated irregular network (TIN) at each loading episode was generated from the point cloud used for such analysis.

\section{Sobradinho landslide}

The landslide slope chosen for the present study is located near a livestock farm close to Ribeirão Contagem river. The watershed of this river has an area of $146 \mathrm{~km}^{2}$ located in the northern part of the Federal District of Brazil in the Sobradinho administrative unit. Maranhão River is the main tributary of the watershed that flows in the north-northeast directions. The drainage and channel densities of the watershed are $5.7 \mathrm{~km} / \mathrm{km}^{2}$ and 32.9 channels $/ \mathrm{km}^{2}$, respectively (Ferreira \& Uagoda 2015). The climate in the area is semi-humid tropical with rainy Summer and dry Winter. The mean 
annual precipitation in the area is of $1,442.5 \mathrm{~mm}$ and it is mainly related to rainfalls.

The landslide is E-W trending roto-translational earth slide (Varnes 1978) and has a mass of approximately $150 \mathrm{~m}$ long and $70 \mathrm{~m}$ wide. Along with the main scarp at the top, there is a small scarp in the middle. Contagem River cuts the slope at its bottom. The engravement potential of this river is related to rainfall in the surrounding areas, which is high during the rainy season.

In order to detect the dynamic behavior of the most active portion of the landslide, a triangular array geometry of three seismometers along with the same acquisition system as of the vertical slope was used. Data were recorded at 250 SPS in a continuous mode with two-time windows: dry (04-11-2017 to 08-11-2017) and saturated (10-12-2017 to 17-12-2017) days (Fig. 2).

\section{Geological and geomorphological settings}

The Federal District covers the eastern part of the Tocantins Province. The Brasiliano orogenic event (end of Neoproterozoic, around $570 \mathrm{Ma}$ ) is divided into five deformational phases, considering the lithostructural changes that occurred in the past (Campos 2004). Towards San Francisco craton, this cycle is characterized as compressive tectonics, presenting the first of these four stages with folds and ductile-brittle faults that made both dome formation (the Brasília, the Pipiripau and Sobradinho domes) and also structural basin creation (FreitasSilva \& Campos 1998). The geology of this area has been revised and updated in the form of a new geological map at 1:100,000 scale (Freitas-Silva \& Campos 1998). In this new map, four lithological boundaries were distinguished:

- Paranoá (metasedimentary rocks), Canastra (phyllites);

- Araxá (schists);
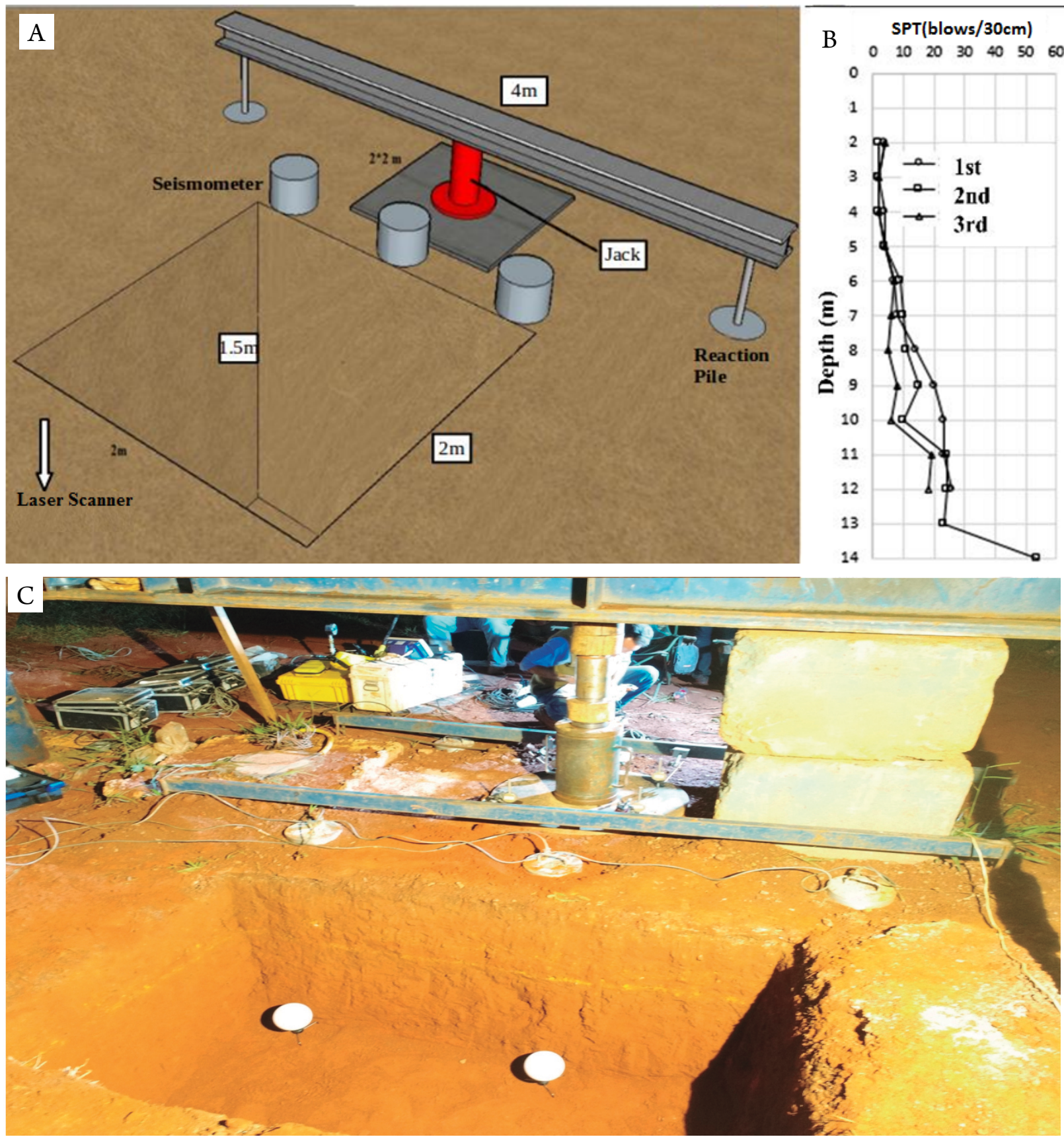

Figure 1. Experimental setup: (A) sketch showing the excavation dimension (vertical slope), reaction piles, positions of seismometers and loading mechanism presentation; (B) SPT-N profile of the area; (C) experiment photograph. 
- Bambuí (clayed metasiltites rolled, clay and metasiltites banks);

- groups and soil or waste shallow colluvial deposits (pedimentary type).

These lithological units are present in reverse successions, in which the younger lithostructural unit lies above the older ones. The geological setting of this succession is mainly related to thrust faulting (Freitas-Silva \& Campos 1998).

The studied area is geologically composed of meta-sedimentary rocks of Proterozoic age that were deformed during the Brasiliano Cycle (650 My), covered by a thick weathering mantle (Zoby 1999). The Sobradinho Unit, of Votorantim Cimentos Brazil, is in the Ribeirão Contagem Basin, in which low-grade metamorphic sediments of the Paranoá and Canastra groups occur. The Federal District, more specifically its north-central portion, is in the domain of the Tocantins Structural Province, in the Brasília Dobramentos Range. In there, rocks are attributed to the Canastra, Paranoá, Araxá and Bambuí groups of Proterozoic ages (Canastra and Paranoá groups $\sim 1,100$ million years old and Araxá and Bambuí groups $\sim 700$ million years old). The geology of the area consists of Paranoá group (metasedimentary rocks).

On the slope of the study area, a small portion of the carbonate sandy pelite unit emerges with the carbonate pellet (Fig. 3A). The rocks that make up this unit are strongly influenced by background paleogeography, marking the final deposition of the Paranoá Basin. The weathering of these deposits occurred when they came in contact with environmental agents, as shown in Fig. 3B. Figures 3A and 3B are photos taken on the drainage margin, showing the contact between the alluvial and
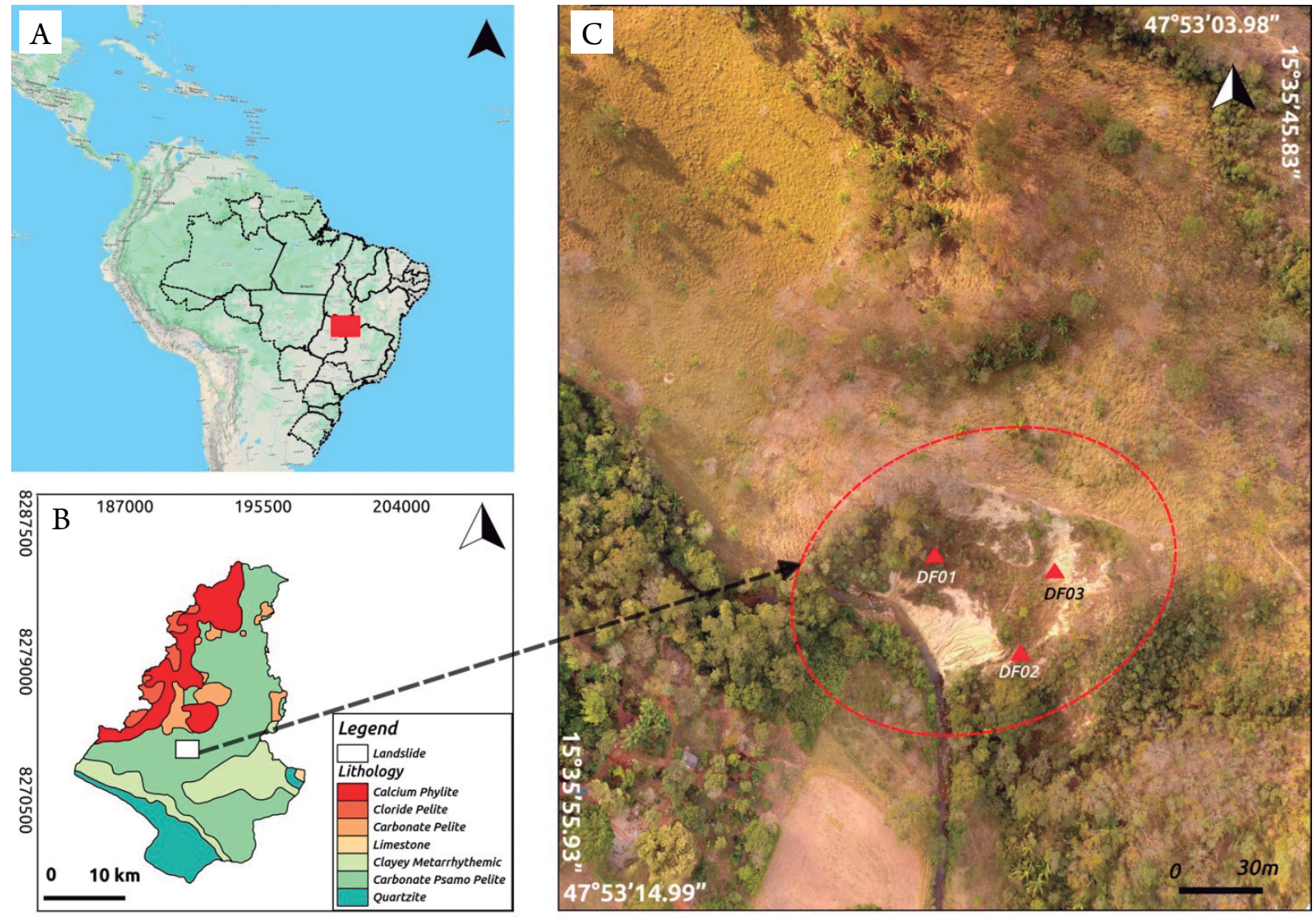

Figure 2. (A) Location of Brazil in the South American map, in which the red rectangle is the Federal District location; (B) lithological units of Contagem basin, in which the white rectangle is the landslide position; (C) zoomed landslide image with triangular array used for timelapse monitoring. The red dashed ellipse is the landslide approximate boundary.
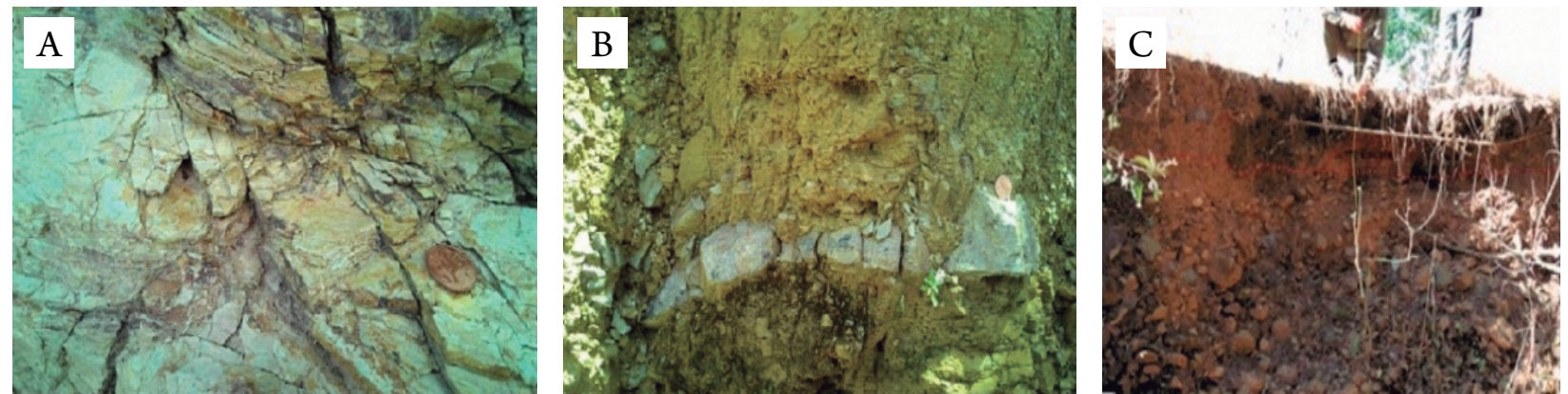

Figure 3. Geology of the area of Sobradinho landslide: (A) outcrops of low degree weathered rocks in the highest elevation areas; (B) saprolite with fragments of quartzite including micaceous minerals; and (C) profile photo with alluvial deposit superimposed on the coarse-grained material. 
colluvial materials. The alluvial with lateral continuity ranging from 30 to $100 \mathrm{~m}$ from the drainage bed detailed can found at Braga et al. (2018). The deposits in the channel of the Contagem River are distinguished by the following materials:

- landslide debris due to recent rotational failure mechanism;

- fluvial deposits on recent riverbanks;

- alluvial fan deposits;

- colluvium;

- alluvium.

\section{Rainfall-induced dynamics of landslides}

Water pore-pressure increase in a porous medium leads to a reduction of the shear strength by counteracting normal stress (Saar \& Manga 2003, Shapiro et al. 2005, Hamza \& Bellis 2008), and the Mohr circle moves closer to the MohrCoulomb failure envelope. A small increase in the effective stress above a critical value may cause failure (Saar \& Manga 2003, Hainzl et al. 2006). Many seismic-based precursors of hydrodynamic phenomena (hydroseismicity) have been discussed in several previous studies, such as aftershock series (Nur \& Booker 1972, Miller et al.2004), reservoir induced and fluid injection-induced earthquakes (Talwani 1997, Zoback \& Harjes 1997), micro-seismicity related to seasonal changes in groundwater flow or stream discharge (Roth et al. 1992, Saar \& Manga 2003), and earthquakes following periods of intense rainfall (Hainzl et al. 2006). Therefore, hydroseismicity can be an effective precursor to provide information of the stress state and hydraulic properties of the medium (Husen et al. 2007).

The degree of saturation and co-related changes of the mass physical and mechanical properties of the landslide can also alter the seismic wave properties. Regarding rainfall, the cracks and pores are filled with water compared to cracks with air, so the velocities are expected to be altered. The $S$ waves do not pass through fluids, while the velocity of $P$ waves increased when traveling through water. These fluid-dependent variations in both $S$ and $P$ waves velocities alter the velocity of surface waves and can, hence, be an indicator of landslide dynamics (landslide precursor). The effects of rainfall-induced pore-pressure and stiffness variation on the dynamics of landslides have been considered in many previous studies with an emitted signal-based method or an ambient noise-based method. In the emitted signal-based method (e.g., Walter et al. 2011, Vouillamoz et al. 2018), microearthquakes associated with the hydrodynamics are localized and characterized using nanoseimic monitoring (Joswig 2008), while in the ambient noise-based method, changes in seismic velocities are measured using ANI. The prominent ambient noise studies are from Mainsant et al. (2012b), Voisin et al. (2016), Harba \& Pilecki (2017), Fores et al. (2018) and Bièvre et al. (2018).

\section{Data processing}

The processing workflows of ANI vary depending on its application. However, most commonly adopted processing schemes (after the preprocessing stage) are autocorrelation, cross-correlation or deconvolution, which retrieves Green's functions from ambient seismic noise at a variety of temporal resolution (Czarny et al. 2016). The ambient noise analysis is carried out in two stages: before the cross-correlation (preprocessing) and computation of cross-correlation.

The following processing steps were conducted during preprocessing (Fig. 4): mean and trends were removed from the data. The data were high-pass filtered. Spectral whitening (flattening) was applied to reduce the effects of highly energetic frequencies in the records. In order to reduce the

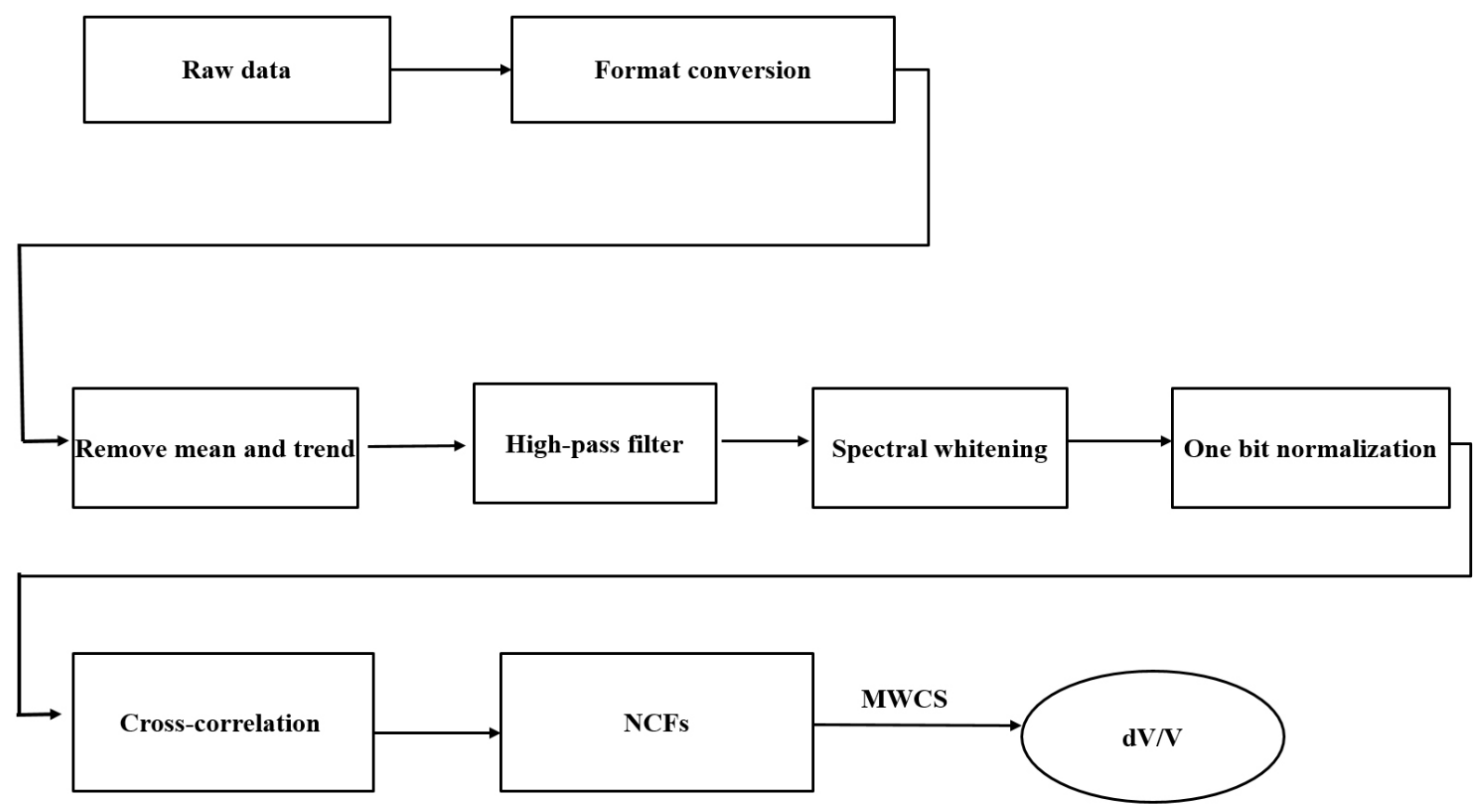

Figure 4. Ambient noise processing workflow starts from raw data and outputs an estimation of changes of relative velocity (dV/V), with NCFs or Empirical Green Function. 
contribution of high energy arrivals that could obscure the lower amplitude ambient noise signal, "one-bit" normalization was applied (Stehly et al. 2007). In this application, each data point was replaced with either a 1 or a -1 value depending on its sign, thereby removing amplitude information completely from the records. One-bit normalization was achieved by dividing each 24-hour record by their absolute value (Jonsdottir 2018). Signals were analyzed in the frequency bands of 2-24 and $2-148 \mathrm{~Hz}$ for Sobradinho landslide and for the man-made vertical slope experiment, respectively. A small segment of raw and preprocessed data is shown in Fig. 5.

\section{Computation of cross-correlation functions}

The cross-correlation functions (CCFs) of continuous ambient noise waveforms are called correlograms. The coda of the correlograms are sensitive to velocity changes and can, therefore, be used to detect small velocity changes in response to stress changes or other changes of the material state (e.g., Clarke et al. 2011). The cross-correlation of the random wavefield recorded at different positions in free space theoretically synthesizes the seismic energy at one location if there had been an impulsive source present at other location. This mechanism is true for any medium, and response is given in terms of Green's function. It provides the medium effects (between two sensors) on impulsive source using travel-time and waveform information of all the phases (Wapenaar 2004, Planès et al. 2015). It measures the wave similarity at different locations using travel time lag $(\tau)$ between the sensors. The cross-correlation of two signals 'a' and 'b', 'Ca,b', is a function of time lag that is commonly defined as it is expressed in Equation 1:

$$
\mathrm{Ca}, \mathrm{b}(\tau)=\int \mathrm{u}(\mathrm{t}, \mathrm{a}) \mathrm{u}(\mathrm{t}-\tau, \mathrm{b}) \mathrm{dt}
$$

In which:

integration = performed over the length of records;

$\mathrm{u}=$ the amplitude of a signal as a function of time.

From Equation 1, 'Ca,b' is maximum when the sum of the products ' $u(t, a) \times u(t-\tau, b)$ ' is maximum, meaning that 'a' and ' $b$ ' are more similar when ' $b$ ' is shifted by that amount relative to 'a' (Jonsdottir 2018).

ANI cross-correlation is a central step that provides the travel times of seismic phases between two sensors. The recorded signals represent the same wavefield shifted in the time taken to reach from one sensor to the second. Therefore, the CCF contains a peak that corresponds to the wavefield travel time between sensors.

Following the preprocessing stage, the records were cross-correlated over an appropriate window length, and results are stacked (Tab. 1). This computational step has paramount importance in ANI. In order to retrieve Rayleigh wave, whose particle motion is confined in the vertical-radial plane, the cross-correlation at vertical $(\mathrm{Z})$ component is computed first. The cross-correlation of all pairs of stations (DF01 to DF02) for ZZ (vertical component), RR (radial component) and TT (transverse component) was obtained (Fig. 6). In the TT direction, we expect the Love wave contribution. The reverse interstation paths are not computed so that the cross-correlation order DF01-DF02 is performed and DF02-DF01 is not, allowing a total of three station pairs for the three stations used.

\section{Moving-window cross-spectral technique}

The moving-window cross-spectral (MWCS) was proposed by Poupinet et al. (1984) and was applied for the calculation of crustal velocities from microearthquakes. The detailed description of the method can be found in Clarke et al. (2011).
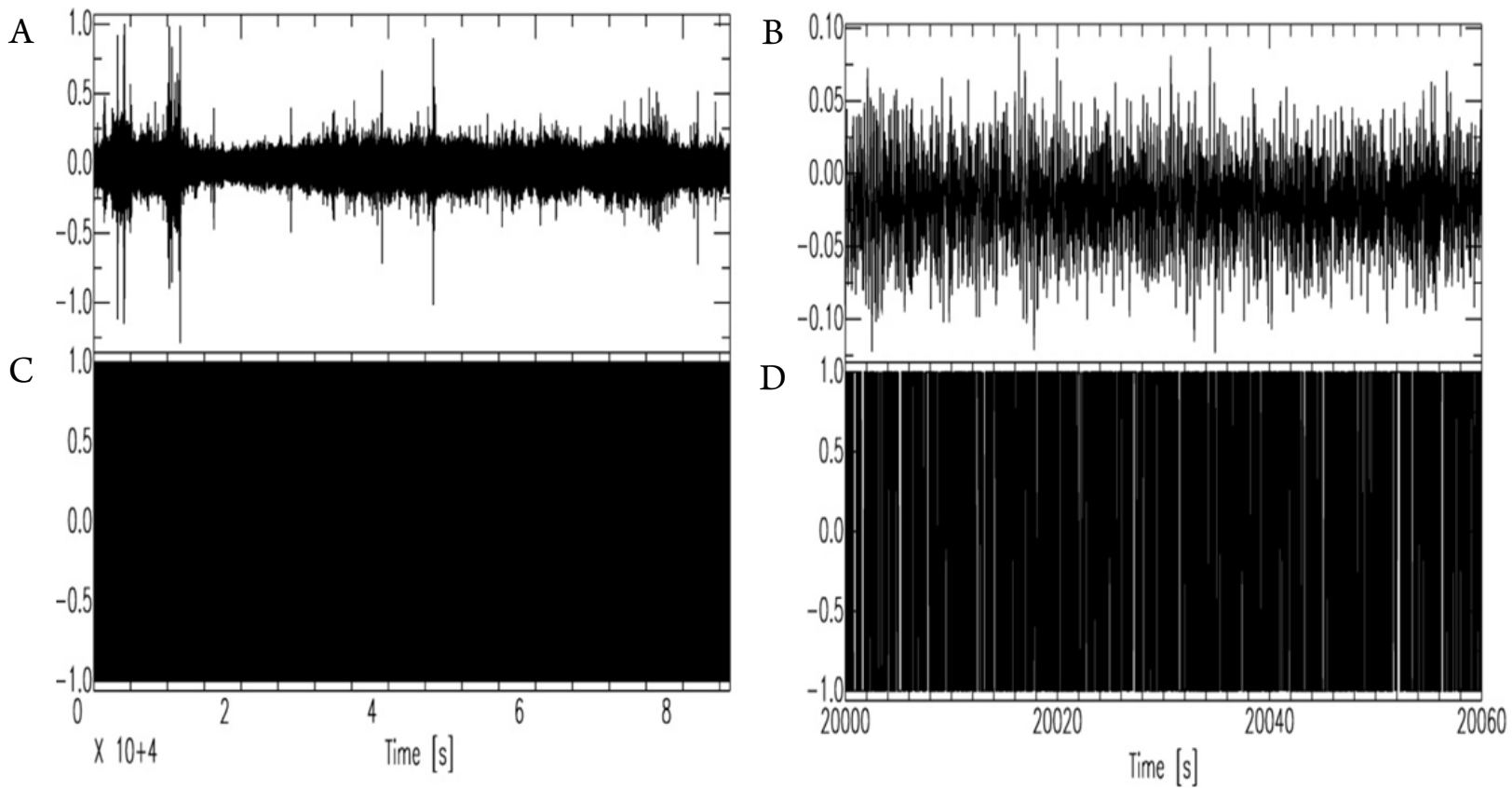

Figure 5. (A) One-hour record of ambient noise; (B) a 3-second segment around a transient event; (C) unprocessed one-hour trace displayed after normalization; (D) a 30-second segment around a transient event after normalization. Units in the figure are arbitrary. 
It is the most adopted method for the calculation of velocity changes in the frequency domain. The MWCS is used for the preprocessed reference (long-term) and current CCFs (short-term), which are divided into small window segments at different lag times. These segments are cosine tapered and mean-adjusted and are Fourier transformed for the calculation in the frequency domain.

The phase differences between the two waveforms are used to estimate the time delays $(\mathrm{dt})$ between the two windowed cross-correlations. The seismic propagation velocity is assumed perturbed uniformly in the area; thus, the time shift becomes constant and phases of cross-spectrum will be linear (Clarke et al.2011). The weighted linear regression is applied to the best fit individual measurements, and local time shift of cross-correlations (CCFref and CCFcur) is calculated from the slope. The CCFs coherences are the factor of weights in regression. The points of similarity in CCFs weigh more in the delay time computation than the points where the similarity of two functions is lower (Jonsdottir 2018).

\section{RESULTS AND DISCUSSION}

\section{Cross-correlation function}

We computed the cross-correlation functions for all station pairs. The pattern of cross-correlation was complex and noisy at the natural scale experiment, and the correlation functions were also not stable with time, which was a possible reason for the results obtained from Sobradinho landslide. However, at the prototype reduced-scale experiment, the cross-correlation was good and less noisy (Fig. 6). The stability of CCF over the recorded length showed much greater coherence and

Table 1. The parameters used for relative velocity changes $(\mathrm{dV} / \mathrm{V})$ estimation at the vertical slope as well as at landslide experiments.

\begin{tabular}{|c|c|c|c|}
\hline Parameter name & Description & Normal slope & Sobradinho landslide \\
\hline analysis_duration & Duration of the analysis $[\mathrm{s}]$ & $3 \mathrm{HRS}$ & UNTIL DAYS \\
\hline cc_sampling_rate & Sampling rate for the cross-correlation $[\mathrm{s}]$ & $(\mathrm{DELTA}=0.001)$ & $(\mathrm{DELTA}=1.600000 \mathrm{e}-02)$ \\
\hline resampling_method & Resampling method & SAC command & SAC command \\
\hline preprocess_lowpass & Preprocessing low-pass value $[\mathrm{Hz}]$ & $80-112$ & $2-24 \mathrm{~Hz}$ \\
\hline preprocess_highpass & Preprocessing high-pass value $[\mathrm{Hz}]$ & $112-150 \mathrm{~Hz}$ & $2-24 \mathrm{~Hz}$ \\
\hline maxlag & Maximum lag time $[\mathrm{s}]$ & $0.6 \mathrm{~s}$ & $0.5 \mathrm{~s}$ \\
\hline corr_duration & Data windows to correlate $[\mathrm{s}]$ & $\begin{array}{l}\text { STACK } 2 \text { s windows } \\
\text { each } 300 \mathrm{~s}(5 \mathrm{~min})\end{array}$ & $\begin{array}{l}\text { STACK } 10 \text { s windows } \\
\text { each } 1800 \text { s }(30 \mathrm{~min})\end{array}$ \\
\hline overlap & Amount of overlap between data windows & 0 & 0 \\
\hline windsorizing & Windsorizing at $\mathrm{N}$ times RMS & None & None \\
\hline whitening & Whiten traces before cross-correlation & Yes & Yes \\
\hline stack_method & Stacking method & Simple, SAC & Simple, SAC \\
\hline components_to_compute & Components & $\mathrm{ZZ}, \mathrm{RR}$ and $\mathrm{TT}$ & $\mathrm{Z}$ \\
\hline
\end{tabular}
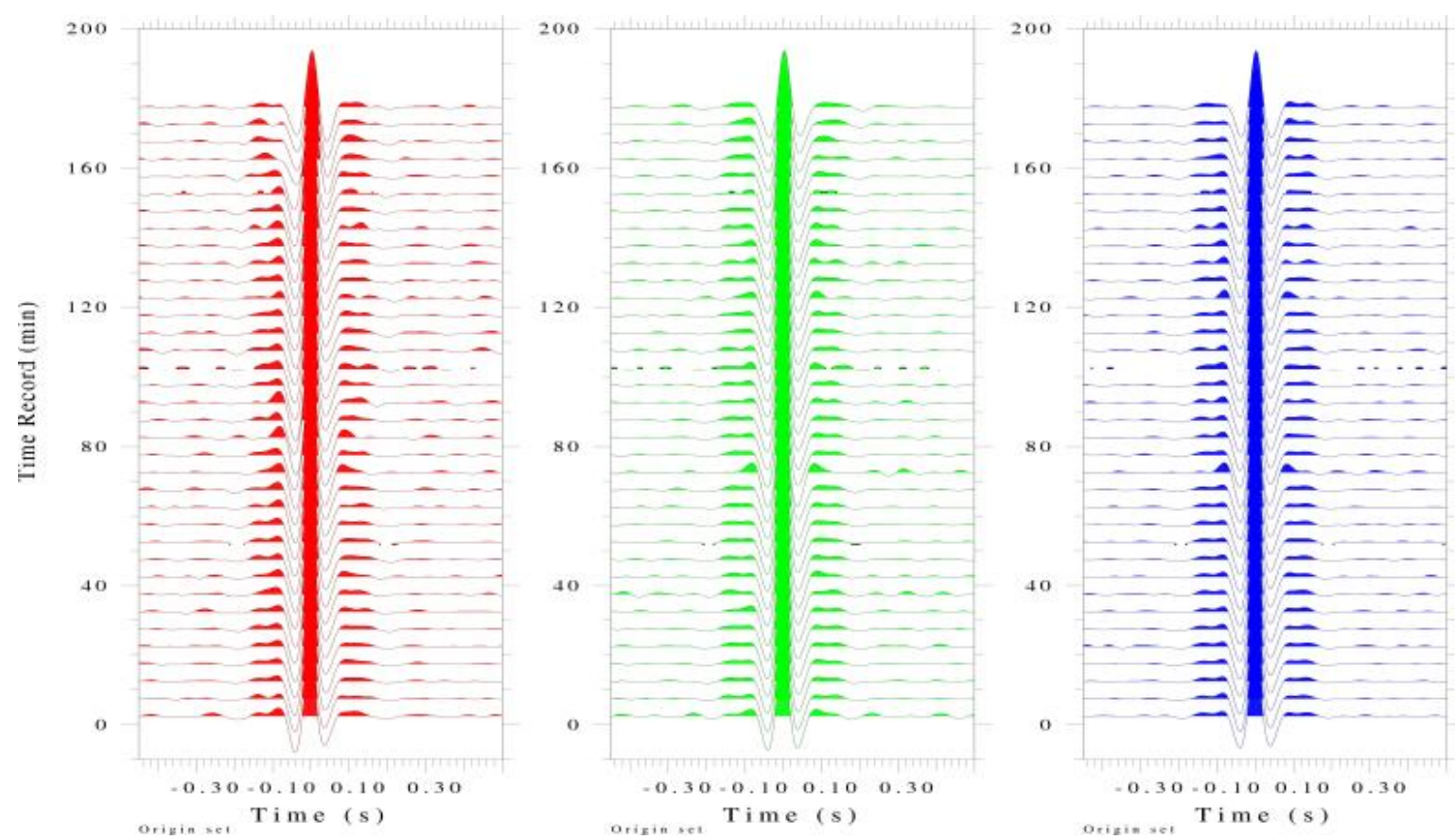

Figure 6. Cross-correlation traces of the prototype vertical slope experiment: ZZ (vertical-vertical), RR (radial-radial) and TT (transverse-transverse) filtered between 6 and $16 \mathrm{~Hz}$. 
symmetry, which is an important quality for reliable velocity change estimation. At first glance, we did not observe significant differences in the waveform for the different components.

\section{Reduced-scaled experiment}

Results of the plate loading test (vertical slope) are shown in Figure 7 and were taken at a causal window interval time of 0.1 second, around 0.15 seconds. In the frequency band of 89-148 Hz (after 1,5 hour of loading), the deformational degree effects are evident. This decrease in the seismic velocity at high frequency is consistent with the rise in the applied load. In response to the applied load, an increase in soil displacement was observed in the extensometers. This displacement is the result of soil micro-fracturing in the vertical slope. These microfractures might have propagated by joining the adjacent microfractures as it usually occurs in the activation or reactivation of landslides. These propagating microfractures lead to a reduction in the seismic velocity as observed in the form of $\mathrm{dV} / \mathrm{V}$. The other effects of the load increase are cracks in the soil that resulted in a decrease in seismic velocity (Hotovec-Ellis et al.2014, Jonsdottir 2018). The sensitivity of seismic with surface loads has also been demonstrated in various previous studies (Mordret et al.2016, Taira \& Brenguier 2016, Mainsant et al. 2012b). Results of the present study are consistent with the previous findings; however, the amount of applied load in the present study is much higher.

The digital elevation model (DEM) of each loading interval is shown in Figure 8. Contrary to the ANI results, no observable changes were detected on DEMs from the beginning to end, mainly because of the absence of centimeter scale fractures on the slope surface. These are also supported by the visual observations during the experiment. There was only an internal soil failure, and changes occurred because of the microfractures developed along the shear surfaces. For future studies, better-planned experiments are recommended, in which all the three stages of slope deformation, i.e. before, during and after the collapse of the vertical slope, can be monitored.

\section{Sobradinho landslide}

In theory, the potential effects of rainfall infiltration are the decrease in $\mathrm{dV} / \mathrm{V}$, which may possibly be related to the rise in pore-pressure and change in rheology of the landslide mass. The infiltrated water can reduce the shear wave velocity through an increase in the degree of saturation; therefore, reducing the soil stiffness and leading to landslide reactivation process. However, in the present study of Sobradinho landslide, there were no clear changes in $\mathrm{dV} / \mathrm{V}$ at a frequency band of $2-24 \mathrm{~Hz}$ in response to the degree of saturation, because the rainfall amounts during the recording period were very small. The lack of dynamic evidence of the landslide site is probably associated with the following shortcomings:

- significant ambient disturbances because of the short time period records;

- not representative meteorological conditions in the considered time-period;

- insignificant time-changing landslide dynamic.

The soil of the regions is highly porous (55\%), and a large amount of water is required to change the soil state. In these conditions, the water would quickly move through the soil and the low elevated part would get saturated first. Nevertheless, very small changes over the dry period were observed (Fig. 9). They might have been produced by the action of river or because of uneven distributions of noise sources around the sensors. An interesting result was that $\mathrm{dV} / \mathrm{V}$ decreased at the end of the day, possibly as a periodic
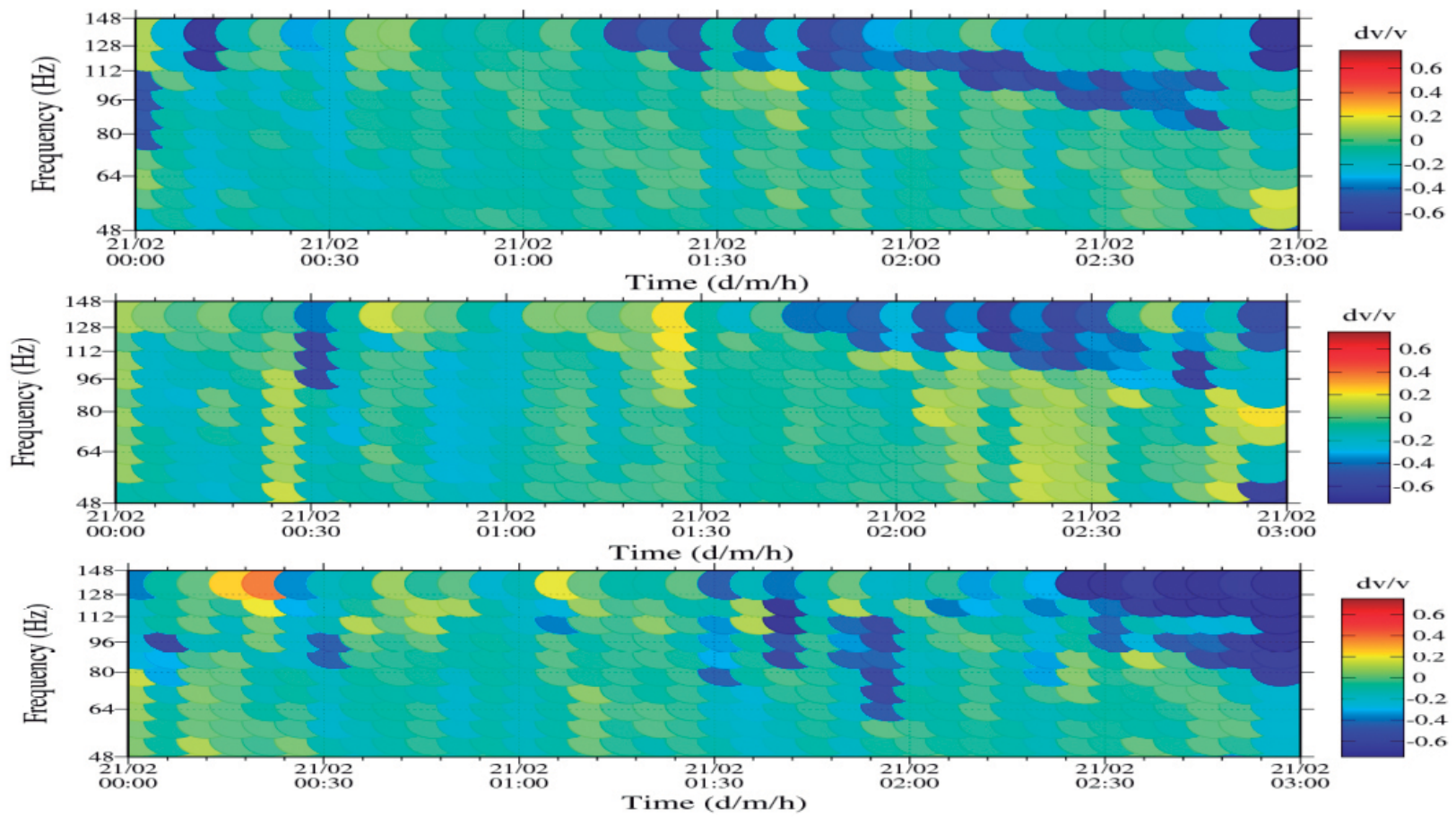

Figure 7. Relative velocity changes between stations PL01-PL02 at RR (top) and TT (middle) and ZZ (bottom) components that represent different stages of plate loading test. The color bar represents relative velocity changes $(\mathrm{dV} / \mathrm{V})$ values. 
effect of the river action. For future studies, longer term acquisition of the field data is recommended in order to overcome the problems of inadequate change soil saturation and ambient noise disturbances. Along with longer ambient noise records, the acquisition of a long and complete time series of the rainfall, pore water pressure, water table fluctuation, soil temperature, moisture measurements at different depths and continuous measurements of the landslide surface (in order to monitor the possible emergence or propagation of fracture) are required for a comprehensive monitoring strategy (Bièvre et al. 2018).
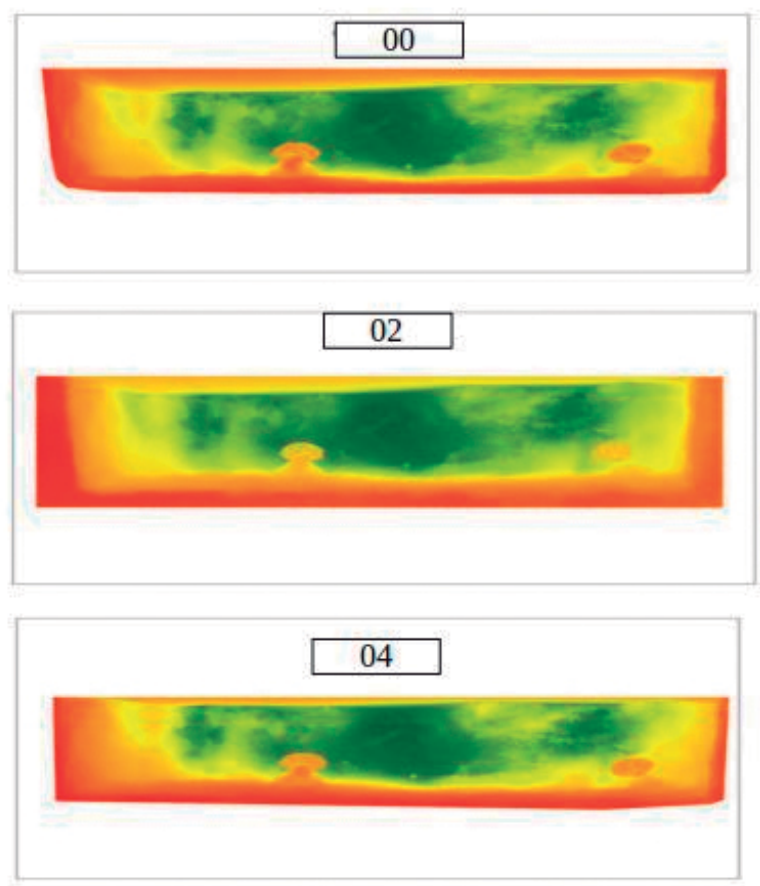

Figure 8. Digital elevation models (DEMs) of the vertical slope surface at 5-minute temporal delays from the beginning (00) to 25 minutes later (05).

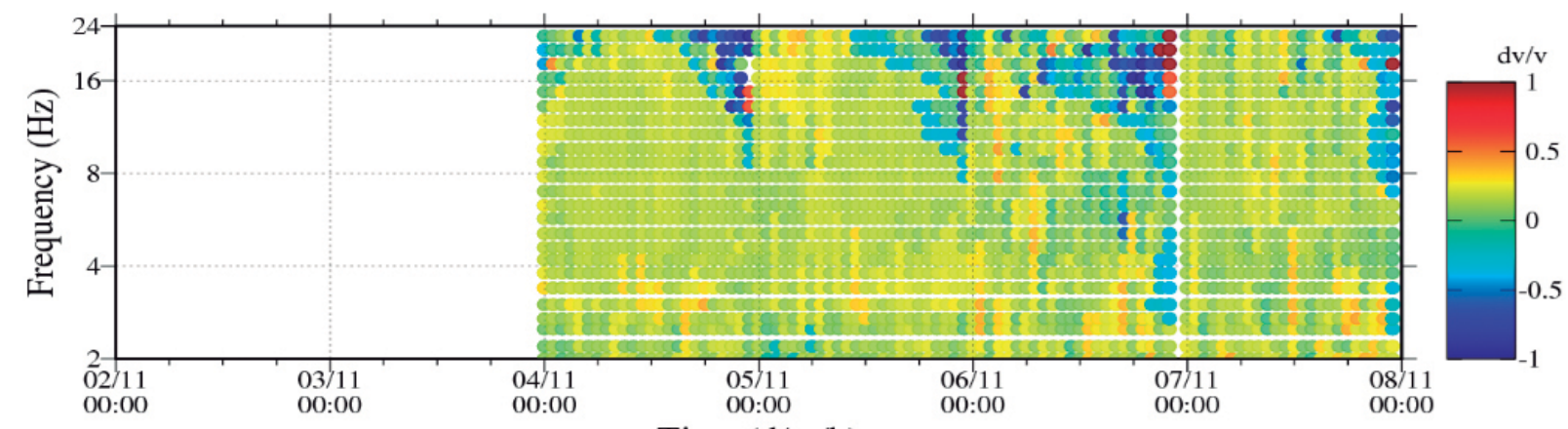

Time $(\mathrm{d} / \mathrm{m} / \mathrm{h})$

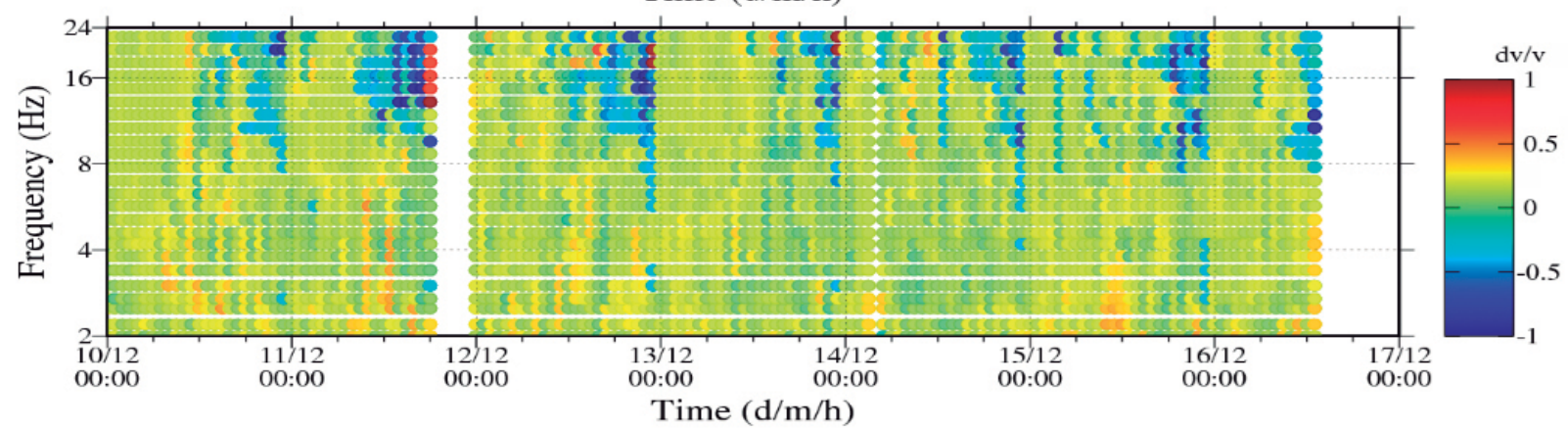

Figure 9. Relative velocity changes between stations DF01-DF02 at ZZ component that represent dry (above) and the wet (below) conditions recorded during the two experimental time windows. The color bar represents relative velocity changes $(\mathrm{dV} / \mathrm{V})$ values. 
- the relative changes in velocity $(\mathrm{dV} / \mathrm{V})$ decreased with the increase of load in the reduced-scale experiment, reaching the absolute value of $-0.6 \%$ at the end of the experiment;

- no change at the surface of the vertical slope was detected by TLS analysis, which may imply that no centimeter scale fissures were developed on the slope surface during the loading;

- no change in the landslide mass was detected in the Sobradinho slope because the rainfall amounts were not enough for the high porosity soil to reach the saturation condition;

- the pattern of cross-correlation was found to be complex and noisy at the natural scale experiment (Sobradinho landslide), and the correlation functions were also not stable with time. However, night effect appeared after $8 \mathrm{~Hz}$ and increased after $16 \mathrm{~Hz}$, as a reflection of the river flow effect.

Future studies on man-made slopes can be beneficial from an improved experimental plan, in which all three stages of slope load-deformation (i.e., before, during and after the collapse) can be monitored. For future studies conducted on a natural-scale landslide, longer-term acquisition of the field data is recommended in order to overcome the problems of inadequate change in soil saturation and ambient noise disturbances. Along with longer ambient noise records, the acquisition of a long and complete time series of rainfall, pore water pressure, water table fluctuation, soil temperature, moisture measurements at different depths and continuous measurements of the landslide surface (in order to monitor the possible emergence or propagation of fracture) are required for a comprehensive monitoring strategy.

\section{ACKNOWLEDGEMENTS}

The authors acknowledge the support of the following agencies: the Brazilian Council for Scientific and Technological Development (CNPq), the Support Research of the Federal District Foundation (FAP-DF), the Universidade de Brasília, and the Pool of Brazilian Equipment (PegBr), Rio de Janeiro. This paper has been partially supported by UNAM projects: PAPIIT (IN117217). The first author is thankful to the Dr. Klebber Teodomiro Martins Ant (Federal University of Goiás - UFG, Goiânia, Brazil) and their students for help in acquisition of Terrestrial Laser Scanning data

\section{ARTICLE INFORMATION}

Manuscript ID: 20180085. Received on: 08/02/2018. Approved on: 03/20/2019.

Y.H. conceived the experiments and acquired the data. Y.H. and M.C.-S. analyzed the data and plotted the figures. O.H., S.M., H.M.-C., J.F.R., R.U. provided reviews and suggestions. Y.H. wrote the paper.

Competing interests: The authors declare no competing interests.

\section{REFERENCES}

Bièvre G., Franz M., Larose E., Carrière S., Jongmans D., Jaboyedoff M. 2018. Influence of environmental parameters on the seismic velocity changes in a clayey mudflow (Pont-Bourquin Landslide, Switzerland). Engineering Geology, 245:248-257. https://dx.doi.org/10.1016/j.enggeo.2018.08.013

Boué P., Poli P., Campillo M., Pedersen H., Briand X., Roux P. 2013. Teleseismic correlations of ambient seismic noise for deep global imaging of the earth. Geophysical Journal International, 194(2):844-848.

Braga L.M., Caldeira D., da Silva Nunes J.G., Hussain Y., Carvajal H.M., Uagoda R. 2018. Caracterização geomorfológica e dinâmica erosivodeposicional de encostas no vale fluvial do Ribeirão Contagem-DF, Brasil. Anuário do Instituto de Geociências - UFRJ, 41(2):51-65.

Campos J.E.G. 2004. Hidrogeologia do Distrito Federal: Bases para a Gestão dos Recursos hídricos Subterrâneos. Revista Brasileira de Geociências, 34(1):41-48.

Claerbout J.F. 1986. Imaging the Earth's interior. Geophysical Journal of the Royal Astronomical Society, 86(1):217-217. https://doi.org/10.1111/ j.1365-246X.1986.tb01086.x

Clarke D., Zaccarelli L., Shapiro N.M., Brenguier F. 2011. Assessment of resolution and accuracy of the Moving Window Cross Spectral technique for monitoring crustal temporal variations using ambient seismic noise. Geophysical Journal International, 186(2):867-882. https://doi. org/10.1111/j.1365-246X.2011.05074.x

Czarny R., Marcak H., Nakata N., Pilecki Z., Isakow Z. 2016. Monitoring Velocity Changes Caused By Underground Coal Mining Using Seismic Noise. Pure and Applied Geophysics, 173(2016):1907-1916. https://doi. org/10.1007/s00024-015-1234-3

Czarny R., Pilecki Z., Drzewińska D. 2018. The application of seismic interferometry for estimating a 1D S-wave velocity model with the use of mining induced seismicity. Journal of Sustainable Mining, 17(4):209-214. https://doi.org/10.1016/j.jsm.2018.09.001

Czarny R., Pilecki Z., Nakata N., Pilecka E., Krawiec K., Harba P., Barnaś, M. 2019. 3D S-wave velocity imaging of a subsurface disturbed by mining using ambient seismic noise. Engineering Geology. 251:115-127. https://doi. org/10.1016/j.enggeo.2019.01.017

D'Hour V. 2015. Medium change monitoring using ambient seismic noise and coda wave interferometry: examples from intraplate NE Brazil and the MidAtlantic Ridge. Doctoral Thesis, Programa de Pós-Graduação em Geodinâmica e Geofísica, Universidade Federal do Rio Grande do Norte, 133 p.

Ehrlich M., da Costa D.P., Silva R.C. 2018. Behavior of a colluvial slope located in Southeastern Brazil. Landslides, 15(8):1595-1613. http://dx.doi. org/10.1007/s10346-018-0964-6

Ferreira R.S. \& Uagoda R. 2015. Morphometric study of controls to Erosional Features and identification of areas susceptible to Mass Movement Hazards in the Contagem Watershed, Distrito Federal. Espaço \& Geografia, 18(1): 187-216.

Fores B., Champollion C., Mainsant G., Albaric J., Fort A. 2018. Monitoring Saturation Changes with Ambient Seismic Noise and Gravimetry in a Karst Environment. Vadose Zone Journal, 17(1). http://dx.doi.org/10.2136/ vzj2017.09.0163

Freitas-Silva F.H. \& Campos J.E.G. 1998. Geologia do Distrito Federal. In: IEMA/SEMATEC/UnB. Inventário Hidrogeológico e dos Recursos Hídricos Superficiais do Distrito Federal. Brasília, IEMA/SEMATEC/UnB, v. 1, Part I. P86.

Grêt A., Snieder R., Özbay U. 2006. Monitoring in situ stress changes in a mining environment with coda wave interferometry. Geophysical Journal International, 167(2):504-508. https://doi. org/10.1111/j.1365-246X.2006.03097.x

Hainzl S., Kraft T., Wassermann J., Igel H., Schmedes E. 2006. Evidence for rainfall-triggered earthquake activity. Geophysical Research Letters, 33(19). https://doi.org/10.1029/2006GL027642

Hamza O. \& Bellis A. 2008. Gault Clay embankment slopes on the A14Case studies of shallow and deep instability. In: Advances in Transportation Geotechnics. Proceedings..., UK, CRC Press, 307 p. 
Harba P. \& Pilecki Z. 2017. Assessment of time-spatial changes of shear wave velocities of flysch formation prone to mass movements by seismic interferometry with the use of ambient noise. Landslides, 14(3):1225-1233. https://doi.org/10.1007/s10346-016-0779-2

Hotovec-Ellis A.J., Gomberg J., Vidale J.E., Creager K.C. 2014. A continuous record of intereruption velocity change at Mount St. Helens from coda wave interferometry. Journal of Geophysical Research: Solid Earth, 119(3):21992214. https://doi.org/10.1002/2013JB010742

Husen S., Bachmann C., Giardini D. 2007. Locally triggered seismicity in the central Swiss Alps following the large rainfall event of August 2005. Geophysical Journal International, 171(3):1126-1134. https://doi. org/10.1111/j.1365-246X.2007.03561.x

Hussain Y., Martinez-Carvajal H., Cárdenas-Soto M., Uagoda R., Martino S., Hussain B.M. 2017. Microtremor response of a mass movement in Federal District of Brazil. Anuário do Instituto de Geociências, 40(3):212-221.

Hussain Y., Martinez-Carvajal H., Condori C., Uagoda R., CárdenasSoto M., Cavalcante A.L.B., Cunha L.S. da, Martino S. 2019. Ambient Seismic Noise: A Continuous Source for the Dynamic Monitoring of Landslides. Terrae Didatica, 15(1):103-107. https://doi.org/10.20396/ td.v15i1.8652455

Jonsdottir F. 2018. Estimation of Relative Seismic Velocity Changes Around Katla Volcano, Using Coda in Ambient Seismic Noise. Thesis, Department of Earth Sciences, Uppsala University, Uppsala, 72 p.

Joswig M. 2008. Nanoseismic monitoring fills the gap between microseismic networks and passive seismic. First Break, 26(6):117-124.

Lin F.C., Tsai V.C., Schmandt B., Duputel Z., Zhan Z. 2013. Extracting seismic core phases with array interferometry. Geophysical Research Letters, 40(6): 1049-1053.

Mainsant G., Jongmans D., Chambon G., Larose E., Baillet L. (2012a). Shear-wave velocity as an indicator for rheological changes in clay materials: Lessons from laboratory experiments. Geophysical Research Letters, 39(19). https://doi.org/10.1029/2012GL053159

Mainsant G., Larose E., Brönnimann C., Jongmans D., Michoud C., Jaboyedoff M. (2012b). Ambient seismic noise monitoring of a clay landslide: Toward failure prediction. Journal of Geophysical Research: Earth Surface, 117(F1). https://doi.org/10.1029/2011JF002159

Milesi V.2016. Potential of ambient seismic noise cross-correlation to characterise the hydrogeology of a clayey landslide: application to Mas D'Avignonet landslide in Trieves region (France). Thesis, School of Civil, Environmental and Terrestrial Engineering, Politecnico Di Milano, Milan, 78 p.

Miller S.A., Collettini C., Chiaraluce L., Cocco M., Barchi M., Kaus B.J.P. 2004. Aftershocks driven by a high-pressure CO 2 source at depth. Nature, 427(6976): 724-727. https://doi.org/10.1038/nature02251

Mordret A., Mikesell T.D., Harig C., Lipovsky B.P., Prieto G.A. 2016. Monitoring southwest Greenland's ice sheet melt with ambient seismic noise. Science Advances, 2(5):e1501538. https://doi.org/10.1126/ sciadv. 1501538

Mota N.M.B. 2003. Ensaios Avançados de Campo na Argila Porosa Não Saturada de Brasília: Interpretação e Aplicação em Projetos de Fundação. Thesis, Departamento de Engenharia Civil e Ambiental, Universidade de Brasília, Brasília, 335 p.

Nakata N., Snieder R., Kuroda S., Ito S., Aizawa T., Kunimi T. 2013. Monitoring a building using deconvolution interferometry. I: Earthquakedata analysis. Bulletin of the Seismological Society of America, 103(3):16621678. https://doi.org/10.1785/0120120291

Nur A. \& Booker J.R. 1972. Aftershocks caused by pore fluid-flow. Science, 175(4024):885-887. https://doi.org/10.1126/science.175.4024.885

Obermann A., Planès T., Larose E., Campillo M. 2013. Imaging pre-eruptive and co-eruptive structural and mechanical changes of a volcano with ambient seismic noise. Journal of Geophysical Research, 118(12):6285-6294. https://doi.org/10.1002/2013JB010399

Olivier G., Brenguier F., de Wit T., Lynch R. 2017. Monitoring the stability of tailings dam walls with ambient seismic noise. The Leading Edge, 36(4):350a1-350a6. https://doi.org/10.1190/tle36040350a1.1

Planès T., Mooney M.A., Rittgers J.B.R., Parekh M.L., Behm M., Snieder R. 2015. Time-lapse monitoring of internal erosion in earthen dams and levees using ambient seismic noise. Geotechnique, 66(4):301-312. http://dx.doi. org/10.1680/jgeot.14.P.268
Poupinet G., Ellsworth W.L., Frechet J. 1984. Monitoring velocity variations in the crust using earthquake doublets: An application to the Calaveras Fault, California. Journal of Geophysical Research: Solid Earth, 89(B7):57195731. https://doi.org/10.1029/JB089iB07p05719

Renalier F., Jongmans D., Campillo M., Bard P.Y. 2010. Shear wave velocity imaging of the Avignonet landslide (France) using ambient noise cross correlation. Journal of Geophysical Research: Earth Surface, 115(F3). https:// doi.org/10.1029/2009JF001538

Roth P., Pavoni N. Deichmann, N. 1992. Seismotectonics of the Eastern Swiss Alps and evidence for precipitation-induced variations of seismic activity. Tectonophysics, 207(1-2):183-197. https://doi. org/10.1016/0040-1951(92)90477-N

Saar M.O. \& Manga M. 2003. Seismicity induced by seasonal groundwater recharge at Mt. Hood, Oregon, Earth Planet. Science Letters, 214(3-4):605618. http://dx.doi.org/10.1016/S0012-821X(03)00418-7

Sens-Schönfelder C. \& Wegler U. 2006. Passive image interferometry and seasonal variations of seismic velocities at Merapi Volcano, Indonesia. Geophysical Research Letters, 33(21):L21302. https://doi. org/10.1029/2006GL027797

Shapiro S.A., Rentsch S., Rothert E. 2005. Fluid-induced seismicity: theory, modeling, and applications. Journal of Engineering Mechanics, 131(9):947-952. https://doi.org/10.1061/ (ASCE)0733-9399(2005)131:9(947)

Snieder R. \& Safak E. 2006. Extracting the building response using seismic interferometry: Theory and application to the millikan library in Pasadena, California. Bulletin of the Seismological Society of America, 96(2):586-598. https://doi.org/10.1785/0120050109

Stehly L., Campillo M., Shapiro N.M. 2007. Traveltime measurements from noise correlation: stability and detection of instrumental time shifts. Geophysical Journal International, 171(1):223-230. https://doi. org/10.1111/j.1365-246X.2007.03492.x

Taira T. \& Brenguier F. 2016. Response of hydrothermal system to stress transients at Lassen Volcanic Center, California, inferred from seismic interferometry with ambient noise. Earth, Planets and Space, 68(1):162. https://doi.org/10.1186/s40623-016-0538-6

Talwani P. 1997. On the nature of reservoir-induced seismicity. In: Talebi S. (Ed.), Seismicity associated with mines, reservoirs and fluid injections. Basel: Birkhäuser, p. 473-492. https://doi. org/10.1007/978-3-0348-8814-1 8

Varnes D.J. 1978. Slope movement types and processes. In: Schuster RL, Krizek RJ (Eds.), Landslides: analysis and control. Spec rep 176. Washington, D.C.: Transportation Research Board, National Research Council, p. 11-33.

Voisin C., Garambois S., Massey C., Brossier R. 2016. Seismic noise monitoring of the water table in a deep-seated, slow-moving landslide. Interpretation, 4(3):SJ67-SJ76. https://doi.org/10.1190/INT-2016-0010.1

Vouillamoz N., Rothmund S., Joswig M. 2018. Characterizing the complexity of microseismic signals at slow-moving clay-rich debris slides: the Super-Sauze (southeastern France) and Pechgraben (Upper Austria) case studies. Earth Surface Dynamics, 6(2):525-550. https://doi. org/10.5194/esurf-6-525-2018

Walter M., Walser M.,Joswig M.2011. Mapping rainfall-triggered slidequakes and seismic landslide-volume estimation at Heumoes slope. Vadose Zone Journal, 10(2):487-495. https://doi.org/10.2136/vzj2009.0147

Wapenaar K. 2004. Retrieving the elastodynamic Green's function of an arbitrary inhomogeneous medium by cross correlation. Physical Review Letters, 93(25). https://doi.org/10.1103/PhysRevLett.93.254301

Wegler U. \& Sens-Schönfelder C. 2007. Fault zone monitoring with passive image interferometry. Geophysical Journal International, 168:1029-1033.

Yfantis G., Martinez Carvajal H.E., Pytharouli S., Lunn R. 2013. Microseismic Monitoring of Induced Slope Failures at Field Scale. In: EGU General Assembly Conference. Abstracts, 15: 511.

Zoback M.D. \& Harjes H.P. 1997. Injection-induced earthquakes and crustal stress at $9 \mathrm{~km}$ depth at the KTB deep drilling site, Germany. Journal of Geophysical Research-Solid Earth, 102(B8):18477-18491. https://doi. org/10.1029/96JB02814

Zoby J.L.G. 1999. Hidrogeologia de Brasilia-DF, Bacia do Ribeirão Sobradinho. Mastering dissertation, Programa de Pós-graduação em Geociências, Universidade de São Paulo, 178 p. 